\title{
Development Of Pocket Tennis Field Course
}

\author{
Irwansyah $^{1)}$, Winarno ${ }^{2)}$ \\ Program Studi Pendidikan Jasmani Kesehatan dan Rekreasi \\ Fakultas Pendidikan Ilmu Eksakta da Keolahragaan \\ ${ }^{1,2}$ IKIP Budi Utomo Malang, Jawa Timur Indonesia \\ Email: ${ }^{1}$ irwansyahhf@gmail.com, ${ }^{2}$ winarno241@ gmail.com
}

\begin{abstract}
Service is one of the materials studied in theoretical and practical course of tennis in the physical education study program, health and recreation, IKIP Budi Utomo Malang. To be able to master the theory and practice of servicing, teaching materials they are needed. The main obstacle for students that is still difficult to practice tennis service. Providing a pocket book is a solution can be done and easy to learn, under everywhere. The pocket book was developed with the Hannafin and Peck development model, which consists of 3 stages, namely (1) Need Assessment (Needs Analysis Phase), (2) Design (Design Phase), and (3) Develop / Implement (Development and Implementation Phase), This development model is a product-oriented learning design model. The data obtained begins with needs analysis, product design, product manufacturing, and product validation. The instrument used to collect development research data used questionnaires and interview guides. Data were analyzed descriptively. Based on the results of the analysis, shows that structured teaching materials have met eligibility requirements. The validity level of the material content experts obtained results of $92 \%$ (very valid), Language obtained results of 96.7\% (Very Valid), Media obtained results of $90.5 \%$ (very valid), and individual trials obtained results with results, $94.5 \%$ (Very Valid) and fit for use.
\end{abstract}

Keywords: Pocket Book, Service, Research

\section{Pengembangan Buku Saku Mata Kuliah Tenis Lapangan ABSTRAK}

Servis merupakan salah satu materi yang dipelajari pada mata kuliah teori dan praktek tenis lapangan pada program studi pendidikan jasmani kesehatan dan rekreasi IKIP Budi Utomo Malang. Untuk dapat menguasai teori dan praktek servis diperlukan bahan ajar. Kendala utama mahasiswa masih sulit mempraktekkan servis tenis lapangan. Menyediakan buku saku merupakan solusi yang bisa dilakukan dan mudah untuk dipelajari, dibawah kemana-mana. Buku saku dikembangankan dengan model pengembagan Hannafin dan Peck, yang terdiri atas 3 tahap, yaitu (1) Need Assessment (Fase Analisis Keperluan), (2) Design (Fase Desain), dan (3) Develop/Implement (Fase Pengembangan dan Implementasi), Model pengembangan ini merupakan model desain pembelajaran yang berorientasi pada produk. Data diperoleh diawali dengan analisis kebutuhan, perancangan produk, pembuatan produk, dan validasi produk. Instrument yang digunakan untuk mengumpulkan data penelitian pengembangan menggunakan angket dan pedoman wawancara. Data dianalisis secara deskriptif. Berdasarkan hasil analisis menunjukkan buku ajar yang disusun telah memenuhi syarat kelayakan. Tingkat validitas dari ahli isi materi diperoleh hasil sebesar 92\% (sangat valid), Bahasa diperoleh hasil sebesar 96,7\% (Sangat Valid), Media diperoleh hasil sebesar 90,5\% (sangat valid), dan Uji coba perorangan diperoleh hasil dengan hasil, 94,5\% (Sangat Valid) dan layak digunakan.

Kata Kunci: Buku Saku, Servis, Penelitian

Info Artikel

Dikirim

Diterima

Dipublikasikan
: 13 Oktober 2020

: 5 November 2020

: 12 November 2020 


\section{PENDAHULUAN}

Proses pembelajaran tidak terlepas dari peran bahan ajar sebagai sumber belajar bagi para mahasiswa, tujuan menyajikan sumber informasi terkini, sumber kegiatan dan kajian lainnya. Bahan ajar sebagai alat informasi yang dibutuhkan oleh guru maupun dosen dalam merencanakan pembelajaran, (Abdul, 2011).

Pembelajaran berbasis penelitian merupakan suatu metode pembelajaran yang berpusat pada siswa yang mensinergikan penelitian dalam proses pembelajaran. Model pembelajaran berbasis research ini dapat dikembangkan sesuai kajian ilmu, karakteristik dan kondisi fasilitas yang tersedia. Cara mengaplikasikan pembelajaran berbasis research perlu dipertimbangkan agar proses pelaksanaan pembelajaran berbasis penelitian efektif/efisien agar mencapai tujuan pembelajaran, (Widayati et al., 2010).

Permainan tenis lapangan merupakan mata kuliah wajib program studi pendidikan jasmani kesehatan dan rekreasi IKIP Budi Utomo Malang. Teori dan praktek tenis lapangan adalah salah satu yang ditempuh mahasiswa pada semester 5 dengan beban 2 SKS. Permainan tenis lapangan adalah permainan dengan memukul kan bola sesudah/sebelum dengan pantulan raket, dengan arah bola melewati atas net masuk ke lapangan lawan, (Sukadiyanto, 2005). Permainan Tenis adalah satu bentuk jenis olahraga yang menggunakan alat berupa raket dan bola sebagai alat permainan, (Siahaan, 2017), Permainan tenis lapangan adalah permainan olahraga dimainkan oleh single atau double, (Prasetiono \& Gandasari, 2018), permainan tenis lapangan adalah olahraga yang permainannya menggunakan raket sebagai alat memukul bola untuk melewati net, (Hazrina Amni, Yati Ruhayati, 2017), permainan tenis yaitu permainan yang menggunakan alat diantaranya raket, net dan bola tenis, dengan berbagai variasi teknik pukulan, (Fadhilul A, 2019), dan adapun tujuan menurut, (Nomor \& Suryono, 2016) permainan tenis lapangan adalah permainan yang berusaha menjatuhkan bola di daerah lawan dengan berusaha agar lawan tidak dapat mengembalikan bola dengan pukulan, Olahraga tenis adalah permainan olahraga dengan menggunakan raket dan bola, (Suganda et al., 2013), Tenis lapangan 
merupakan olahraga yang dimainkan oleh dua pemain atau dua pasangan, (Kardiawan et al., 2018).

Proses perkuliahan tenis lapangan selama ini menggunakan metode presentasi, praktek, serta tanya jawab dan ditunjang dengan berbagai sumber belajar seperti buku ajar, serta jurnal yang dirujuk dosen pengampu mata kuliah teori dan praktek tenis lapangan. Yang menjadi masalah adalah mahasiswa masih sangat kesulitan dalam mempelajari materi servis, dimana materi servis merupakan suatu materi yang sulit untuk dipelajari. Servis merupakan setiap pukulan awal untuk mengawali suatu permainan (Irwansyah, 2018), dan (Alim, 2014) mengatakan bahwa servis merupakan teknik dasar dalam permainan tenisyang digunakan sebagai tanda permainan dimulai. (Jones \& Angela Buxton, 2008) berpendapat bahwa untuk meningkatkan servis menjadi lebih kuat, servis terbaik didasarkan pada gerakan melempar.

Hasil analisis kebutuhan awal melalui penyebaran angket dan wawancara pada tanggal 05 maret 2020 jam 08:30 dan jam 14:50 terhadap dosen dan mahasiswa yang memprogram mata kuliah teori dan praktek tenis lapangan 91,50\% memerlukan buku khusus terkait servis, dari permasalahan tersebut diperlukan solusi dengan pengembangan buku saku tenis lapangan pada materi servis. Buku saku merupakan buku berukuran kecil/mini yang simpel dan mudah di bawah kemana-mana (kamus bahasa Indonesia). Buku yang dikembangkan pada penelitian ini berukuran $13 \mathrm{~cm} \times 19 \mathrm{~cm}$ sehingga mempermudah untuk dibawa dan uraian bacaan relatif pendek. Dalam segi sajian buku saku ini menampilkan gambar dan warna yang menarik. Mahasiswa menyukai buku bacaan dengan sedikit uraian dan banyak menampilkan gambar atau warna, seiring dengan pendapat, (Chatarina, 2017) menyatakan bahwa gambar bisa meninggikan minat baca, gambar bisa membuat pembaca berimajinasi, dan seseorang dapat meningkatkan daya ingatnya dengan berimajinasi, (Sugiyono, 2015), serta dapat menunjang dalam daya ingat kata-kata verbal (Slavin, 2012). Dalam sisi lain warna bisa menjadi alat interaksi (komunikasi) non-verbal yang secara cepat dan bermakna dalam menyampaikan pesan, (Anna, 2011). Sajian materi dalam bacaan ditelaah oleh narasumber sehingga terhindar dari kesalahan dalam hal konsep. 
Adapun beberapa penelitian terdahulu yang relevan diantaranya penelitian pengembangan model servis pembelajaran tenis lapangan efektif dalam meningkatkan partisipasi mahasiswa dalam proses pembelajaran, (Setyawan, 2018), power otot lengan dan kekuatan genggaman memiliki hubungan terhadap hasil servis slice permainan tenis lapangan, (Sukadiyanto, 2005), Pengembangan Perangkat Alat Ukur Kekuatan Servis Bola Tenis Lapangan Berbasis Sensor Digital sebagai acuan untuk melatih kekuatan servis, (Kardiawan et al., 2018), pentingnya penguasaan keterampilan servis usia 12 - 14 tahun dalam menunjang prestasi atlet adalah keterampilan service ketepatan tenis, (Prasetiono \& Gandasari, 2018), Perlu model latihan servis yang tepat agar dapat meningkatkan kecepatan hasil pukulan servis, (Kurdi \& Qomarrullah, 2020), kecepatan reaksi tangan dan koordinasi mata tangan memiliki hubungan terhadap ketepatan dalam melakukan servis, (Kurdi \& Qomarrullah, 2020), buku saku yang dikembangkan (Meikahani \& Kriswanto, 2015) SMP N 4 Depok Yogyakarta tentang pengenalan pertolongan dan perawatan cedera olahraga menunjukkan buku saku efektif dalam meningkatkan pemahaman siswa. Latihan servis twist jarak bertahap dan jarak tetap dapat meningkatkan ketepatan servis twist pada pemain tenis, (Prasetyo, 2017).

Penelitian pengembangan ini dilakukan bertujuan menghasilkan suatu produk berupa buku saku servis tenis lapangan yang dapat dimanfaatkan sebagai buku penunjang bagi mahasiswa program studi pendidikan jasmani kesehatan dan rekreasi IKIP Budi Utomo Malang dalam mempelajari mata kuliah tenis lapangan.

Secara umum buku adalah kumpulan kertas yang tercetak dan terjilid berisi informasi bisa dijadikan sumber belajar. Buku saku adalah buku dengan ukuran kecil, ringan, dan bisa disimpan di saku. Buku saku termasuk media cetak, yang mana media cetak merupakan bahan-bahan yang disiapkan untuk pengajaran dan informasi. Buku saku bisa memberikan stimulus kepada siswa untuk belajar, diharapkan siswa bisa menguasai isi dari buku tersebut.

Fungsi buku menurut (Arsyad Azhar, 2001) adalah materi pelajaran yang dirancang sedemikian rupa sehingga mampu memenuhi kebutuhan siswa/mahasiswa baik cepat maupun lambat membaca dan memahami. Buku 
saku mempunyai manfaat dalam pembelajaran, dan penyampaian pelajaran jadi lebih baku meskipun guru/dosen menyampaikan dengan tafsiran yang berbeda. Dengan buku ini pembelajaran jadi lebih menarik, karena dengan bantuan buku saku siswa/mahasiswa bisa tetap terjaga dan memperhatikan. buku dibuat simple, dengan kata yang runtut ditambah dengan gambar sebagi pendukung materi diharapkan agar bisa menimbulkan rasa keingintahuan siswa/mahasiswa dan bisa meningkatkan motivasi siswa dalam belajar.

Menurut (Suroso, 2007), langkah dalam menulis buku sebagai berikut, (1) merumuskan tujuan dan mempelajari keadaan siswa. (2) Memilih dan menyusun topik, sebagai rujukan arah pem-bahasan isi buku. (3) Mencari sumber referensi dari buku, jurnal dan sebagainya. (4) Membuat rancang rupa (book desain) untuk kemudian diprint out menjadi bundel hardcopy.

Rancangan buku saku Menurut (Wayan Ardhana dan Verna Wills, n.d.), mempunyai beberapa kelebihan seperti, (1) ekonomis, yaitu biaya yang dikeluarkan dalam pembuatan lebih murah dibanding media audio visual. (2) mampu mengatasi keterbatasan ruang dan waktu. (3) mampu mengatasi keterbatasan ruang dan waktu. (4) dapat dibuat model rangkuman atau terperinci karena banyak mengulas tentang materi yang disampaikan.

Produk yang berupa buku saku berukuran 13x19 cm dirancang khusus untuk memenuhi kebutuhan mahasiswa PJKR IBU dalam mempelajari mata kuliah teori dan praktek tenis lapangan sehingga mahasiswa memiliki pengetahuan dan mampu melakukan servis dengan baik, buku saku ini karena berukuran kecil membuatnya jadi simpel dan mudah untuk di bawa kemanamana, terlebih jika pebelajaran dilakukan dilapangan bisa di buka sewaktu dibutuhkan. jika dibandingkan dengan buku tenis lapangan pada umunya yang berukuran besar membuat mahasiswa kesulita menggunakan ketika proses pembelajaran praktek yang dilakukan di lapangan, oleh karena itu sangat cocok buku yang berukuran mini dalam hal ini buku saku servis untuk proses pembelajaran praktek di lapangan. 


\section{METODE}

Penelitian yang di gunakan merupakan penelitian pengembangan. Menurut pendapat yang diutarakan oleh (Winarno M.E, 2011) pengembangan atau yang sering disebut sebagai penelitian pengembangan.

Penelitian pengembangan merupakan penelitian yang berupaya mengembangkan produk tertentu sesuai dengan kebutuhan masyarakat saat ini. Pengembangan yang digunakan pada penelitian ini adalah model pengembangan Hannafin dan Peck, yang terdiri atas 3 tahap, yaitu (1) Need Assessment (Fase Analisis Keperluan), (2) Design (Fase Desain), dan (3) Develop/Implement (Fase Pengembangan dan Implementasi).

Penelitian ini dilaksanakan di IKIP Budi Utomo malang pada bulan Maret Mei 2020. Subjek dalam uji coba adalah ahli materi, bahasa, media pembelajaran, dan uji keterbacaan yang terdiri atas 50 mahasiswa program studi pendidikan jasmani kesehatan dan rekreasi IKIP Budi Utomo Malang yang sedang memprogram mata kuliah tenis lapangan.

Instrumen dalam penelitian berupa angket ahli materi, bahasa Indonesia, ahli media pembelajaran dan mahasiswa yang memprogram mata kuliah tenis lapangan. Data yang diperoleh dalam pelaksanaan penelitian ini terdiri atas data kualitatif dan kuantitatif. Data kualitatif seperti komentar dan saran-saran, sedangkan kuantitatif datanya berupa nilai dengan rentang 1-4 yang di isikan pada lembar angket.

Hasil dari masukan yang berupa komentar maupun sarandari para ahli-ahli dan mahasiswa sebagai data kualitatif dianalisis sebagai acuan untuk melakukan revisi terhadap produk yang dikembangkan. Hasil yang diperoleh dari pengisian angket validasi sebagai data kuantitatif dianalisis dengan menghitung persentase hasil dengan menggunakan rumus berikut ini.

$$
\mathrm{P}=\frac{\sum \mathrm{X}}{\sum \mathrm{Xi}} \times 100 \%
$$

Diketahui :

$\mathrm{P} \quad$ : persentase

$\sum X \quad$ : total hasil jawaban perbutir

$\sum X i \quad$ : total hasil maksimal per butir 
Data hasil analisi yang diperoleh lalu disimpulkan dan ditafsir sesuai acuan dengan kriteria kualifikasi penilaian yang diadopsi dari (Akbar, 2013), ketentuan sebagai berikut.

Tabel 1. Kriteria validasi analisis porsentase

\begin{tabular}{ccl}
\hline No & Kriteria & \multicolumn{1}{c}{ Tingkat Validitas } \\
\hline $\mathbf{1}$ & $01,00-50,00 \%$ & Tidak valid, (tidak boleh digunakan) \\
$\mathbf{2}$ & $50,01-70,00 \%$ & Kurang valid, (disarankan tidak dugunakan revisi besar) \\
$\mathbf{3}$ & $70,01-85,00 \%$ & Cukup valid, (dapat digunakan namun revisi kecil) \\
$\mathbf{4}$ & $85,01-100 \%$ & Sangat Valid, (dapat digunakan revisi kecil) \\
\hline
\end{tabular}

\section{HASIL DAN PEMBAHASAN}

Model pengembangan Hannafin dan Peck, yang terdiri atas 3 tahap, yaitu (1) Need Assessment (Fase Analisis Keperluan), (2) Design (Fase Desain), dan (3) Develop/Implement (Fase Pengembangan dan Implementasi). Model pengembangan ini merupakan model desain pembelajaran yang berorientasi pada produk (Afandi, 2011). Hasil dari setiap tahapan pengembangan yang sudah dilakukan diuraikan sebagai berikut.

a. Analisis

Hasil analisis kebutuhan meliputi sumber belajar, metode pembelajaran dan SKS pada program studi pendidikan jasmani kesehatan dan rekreasi IKIP Budi Utomo Malang telah disajikan dan diuraikan pada latar belakang masalah.

b. Desain dan Pengembangan

Perancangan draft buku saku yang dilakukan pada tahap desain direalisasikan pada tahap pengembangan yang telah disesuaikan dengan analisis kebutuhan kondisi mahasiswa.

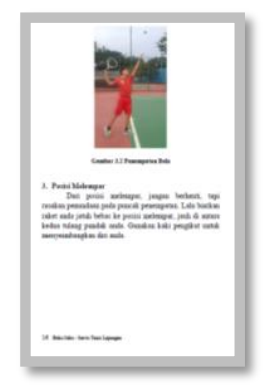

Gambar 1 Tampilan isi buku

c. Implementasi

Tahap implementasi merupakan tahap untuk uji coba produk. Hasil uji coba produk pengembangan sebagai berikut. Pertama, spesifikasi Produk yang 
dihasilkan pada buku saku berbasis penelitian servis pada mata kuliah teori dan praktek permainan tenis lapangan yang telah dikembangkan terdiri dari Cover, Prakata, Daftar isi, Bab I: Pendahuluan, Bab II: Teknik dasar permainan tenis lapangan, Bab III: Servis tenis lapangan, Bab IV: Prosedur penelitian servis, dan Bab V: Penutup dan Daftar pustaka yang bisa dijadikan rujukan mahasiswa untuk memperoleh materi lain.

Pada tahap' implementasi merupakan tahap untuk melakukan uji coba produk yang sudah dibuat. Hasil uji produk pengembangan buku saku berikut ini: Pertama spesifikasi produk yang dihasilkan dalam buku saku servis tenis lapangan dikembangkan. Kedua, Uji coba produk terhadap ahli materi, penyajian data kuantitatif hasil uji coba ahli materi disajikan tabel berikut

Tabel 2. Data kualitatif dari ahli materi

\begin{tabular}{lcc}
\hline Aspek penilaian & Hasil & Kulifikasi \\
\hline Bab 1 Pendahuluan & $85 \%$ & Sangat Valid \\
Bab 2 Teknik dasar permainan tenis lapangan & $90 \%$ & Sangat Valid \\
Bab 3 Servis dalam tenis lapangan & $95 \%$ & Sangat Valid \\
Bab 4 Menjelaskan prosedur penelitian servis tenis & $90 \%$ & Sangat Valid \\
lapangan & & \\
Bab 5 Penutup & $100 \%$ & Sangat Valid \\
\hline
\end{tabular}

Tabel 3. Data Kualitatif dari ahli materi

\begin{tabular}{cl}
\hline Validator & \multicolumn{1}{c}{ Kritik dan Saran } \\
\hline Ahli Materi & 1. Bagian 1 harus ada tujuan agar terarah \\
Pembelajaran & 2. Bagian 2 teknik dasar harus dibahas lebih rinci \\
& 3. Bagian 3 model latihan servis harus dibuat dari yang palin \\
& sederhana seperti dalam prinsip latihan \\
& 4. Gambar-gambar yang kurang jelas harap diperhatikan \\
& 5. Tanda baca dan kutipan lebih diperhatikan \\
\hline
\end{tabular}

Tabel 2 menunjukkan bahwa penelitian pada Bab 1 Pendahuluan dalam proses penyusunan buku saku ini sudah terurai dengan jelas permasalahan dan tujuannya memperoleh hasil sebesar $85 \%$. Begitu dengan isi materi, kebenaran konsep pada Bab dua Teknik dasar permainan tenis lapangan sebesar 90\%, Bab 3 servis dalam tenis lapangan sebesar 95\%, dan Bab 4 dengan materi prosedur penelitian sebesar 90\%, dan Bab 5 penutup sebesar 100\%, dan secara keseluruhan rata-rata dari narasumber isi materi sebesar $92 \%$. 
Tabel 4 Data Kuantitatif ahli' media pembelajaran

\begin{tabular}{|c|c|c|c|}
\hline \multicolumn{2}{|c|}{ Aspek penilaian } & Rata-rata & Kualifikasi \\
\hline \multicolumn{2}{|l|}{ Desain cover } & $80 \%$ & Sangat Valid \\
\hline \multicolumn{2}{|c|}{ Desain isi buku saku } & $95 \%$ & Sangat Valid \\
\hline \multicolumn{2}{|c|}{ Tampilan buku saku } & $98 \%$ & Sangat Valid \\
\hline \multicolumn{2}{|c|}{ Kejelasan gambar } & $89 \%$ & Sangat Valid \\
\hline \multicolumn{4}{|c|}{ Tabel 5 Data Kualitatif dari ahli media pembelajaran } \\
\hline \multicolumn{2}{|l|}{ Validator } & \multicolumn{2}{|c|}{ Kritik dan saran } \\
\hline \multirow{5}{*}{$\begin{array}{c}\text { Ahli Media } \\
\text { Pembelajaran }\end{array}$} & \multicolumn{3}{|c|}{ 1. Desain Cover harus lebih menarik lagi } \\
\hline & \multicolumn{3}{|c|}{ 2. Pemilihan warna juga diperhatikan } \\
\hline & \multicolumn{3}{|c|}{ 3. Ukuran buku terlalu kecil } \\
\hline & \multicolumn{3}{|c|}{ 4. garis pinggir tidak perlu ada } \\
\hline & \multicolumn{3}{|c|}{ 5. ada beberapa gambar yang masih kurang jelas } \\
\hline
\end{tabular}

Tabel 4 menampilkan hasil evaluasi ahli media pembelajaran mengenai desain cover yang meliputi:Grafis, Warna, serta sajian gambar dengan hasil $80 \%$. Desain isi yang disajikan meliputi penyusunan kalimat, paragraf, tata letak, judul, dan keterangan gambar yang disajikan dengan hasil 95\%, kaidah dalam penulisan meliputi tampilan buku, pemakaian bahasa, dengan hasil 98\%, dan kelayakan penyajian buku, (gambar), dengan hasil 89\%, dan secara keseluruhan rata-rata dari narasumber media pembelajaran sebesar 90,5\%.

Tabel 6 Data Kuantitatif uji ahli bahasa Indonesia

\begin{tabular}{lcc}
\hline \multicolumn{1}{c}{ Kriteria penilaian } & Rata-rata & Kualifikasi \\
\hline Teknik penulisan & $98 \%$ & Sangat Valid \\
Penggunaan Bahasa & $95 \%$ & Sangat Valid \\
Penggunaan Tanda dan simbol-simbol penulisan & $97 \%$ & Sangat Valid \\
\hline
\end{tabular}

Tabel 7 Data Kualitatif dari uji ahli bahasa Indonesia

\begin{tabular}{cll}
\hline Validator & \multicolumn{2}{c}{ Kritik/saran } \\
\hline Ahli & 1. & Perhatikan tanda baca (Titik, Koma) masih banyak kesalahan \\
Bahasa & 2. & Masih ada beberapa kata yang salah dalam pengetikan \\
Indonesia & & \\
\hline
\end{tabular}

Tabel 6 menunjukkan hasil penilaian dari validasi ahli bahasa Indonesia terkait teknik penulisan memperoleh hasil sebesar 98\%. Penggunaan bahas memperoleh hasil sebesar 95\%, penggunaan tanda dan simbol-simbol memperoleh hasil sebesar 97\%, dan secara keseluruhan rata-rata dari narasumber bahasa Indonesia sebesar 96,7\%.

\section{Uji' Perorangan (kelompok kecil)}

Setelah memperoleh masukkan dari ahli materi, media dan bahasa Indonesia dilakukan uji coba perorangan. Subjek yang menjadi uji coba pada 
tahap ini adalah 50 mahasiswa semester 6 pada program studi pendidikan jasmani kesehatan dan rekreasi IKIP Budi Utomo Malang yang memprogram mata kuliah tenis lapangan. Hasil uji coba perorangan disajikan pada berikut.

Tabel 8: Data Kuantitatif hasil uji Coba Perorangan

\begin{tabular}{lcl}
\hline \multicolumn{1}{c}{ Aspek penilaian } & Rata-rata & \multicolumn{1}{c}{ Kualifikasi } \\
\hline Kemenarikan buku saku & 98 & Sangat Valid \\
Kemudahan materi & 95 & Sangat Valid \\
Pemahaman materi & 90 & Sangat Valid \\
Keterbaruan materi & 95 & Sangat Valid \\
\hline
\end{tabular}

Tabel 8 menunjukkan hasil validasi uji coba perorangan yang dilakukan pada 50 mahasiswa (sebagai subjek) program studi pendidikan jasmani kesehatan dan rekreasi yang menduduki semester 6 untuk validasi dalam hal Kemenarikan buku saku yang disajikan meliputi, kemenarikan aspek materi dan motivasi, menampilkan media foto serta uraian gambar dengan hasil $95 \%$, kemudahan materi, seperti bahasa buku saku dengan hasil 98\%. Pemahaman materi mencakup keterkaitan antara konsep dengan materi, serta keterpaduan bagianbagian, serta penyampaian pesan dengan hasil $90 \%$, dan keterbaharuan materi (isi), diantaranya hal-hal baru dan juga pemantapan konsep dengan skor 95\%. Hasil keseluruhan aspek diperoleh untuk uji coba perorangan dengan skor 94,5\% sehingga dikategorikan valid.

Dengan buku saku berbasis penelitian servis yang dikembangkan untuk mata kuliah teori dan praktek tenis lapangan diharapkan mahasiswa mendapatkan informasi update terkait penunjang dan sumber materi yang lebih dinamis. Hasil validasi dan respon mahasiswa terhadap buku saku yang disajikan mendapat respon yang sangat positif. Mahasiswa menganggap bahwa buku saku berbasis penelitian servis bisa menjadi informasi mengenai hasil. Oleh sebab itu informasi dari hasil penelitian bisa dimuat dalam bentuk buku berbasis penelitian dengan ditopang oleh pustaka yang relevan.

Buku saku berbasis penelitian servis ini dihasilkan berisi materi tentang pendahuluan terkait tenis lapangan, dasar-dasar permainan tenis lapangan, servis permainan tenis lapangan, prosedur penelitian servis tenis lapangan, dan penutup. Buku saku ini telah divalidasi narasumber bahasa Indonesia, narasumber media pembelajaran, dan narasumber isi materi, dan uji coba perorangan, yang ditujukan kepada mahasiswa S-1 pendidikan jasmani kesehatan dan rekreasi. 
Hasil dari ketiga validasi narasumber menunjukkan buku saku berbasis penelitian servis ini sudah valid dan layak digunakan sebagai referensi penunjang dalam pembelajaran.

\section{SIMPULAN}

Dalam penelitian ini dihasilkan buku saku berbasis penelitian servis untuk matakuliah teori dan praktek tenis lapangan dengan persentase dari narasumber ahli materi (isi) sebesar 92\% (sangat valid), ahli bahasa Indonesia sebesar 96,7\% (sangat valid), ahli media pembelajaran sebesar 90,5\% (sangat valid), dan uji coba perorangan diperoleh hasil sebesar 94,5\% (sangat valid).

\section{DAFTAR RUJUKAN}

Abdul, M. (2011). Perencanaan pembelajaran mengembangkan standar kompetensi guru. Bandung: PT Remaja Rosdakarya.

Afandi, M. dan B. (2011). Perencanaan Pembelajaran. Bandung: Alfabeta.

Akbar, S. (2013). Instrumen Perangkat Pembelajaran. Bandung: Remaja Rosdakarya.

Alim, A. (2014). Analisis Gerak Teknik Servis Tenis Lapangan. Universitas Negeri Yogyakarta.

Alimi, F. (2019). Pengaruh Metode Elementer terhadap Keterampilan Pukulan Forehand Pemain Tenis Pemula PTL UNP (Doctoral dissertation, Universitas Negeri Padang).

Amni, H., Ruhayati, Y., \& Sultoni, K. (2017). Pengembangan Teknologi Alat Pelontar Bola Tenis Lapangan Berbasis Microcontroller. Jurnal Terapan Ilmu Keolahragaan, 2(1), 18-24.

Anna, L. K. (2011). Pengaruh Warna pada Emosi. Jurnal Online).(www. kompas. com). Diakses, 9.

Aprilia, N. (2018). Pengembangan Buku Cerita Bergambar Berbasis Pendidikan Lingkungan Hidup Untuk Pembelajaran Membaca di Kelas II SD. Pengembangan Buku Cerita Bergambar Berbasis Pendidikan Lingkungan Hidup Untuk Pembelajaran Membaca di Kelas II SD.

Arsyad Azhar. (2001). Media Pembelajaran. Jakarta: Raja Grafindo Persada.

Ibana, L. (2015). Mikroalga sebagai bioindikator pencemaran perairan di waduk Selorejo untuk pengembangan buku referensi biologi (Doctoral dissertation, Universitas Negeri Malang). 
Irwansyah, I. (2018). Pengembangan Buku Ajar Teori Tenis Meja Bagi Mahasiswa Kelas A 2016 Jurusan PJKR IKIP Budi Utomo Malang. Jp. jok (Jurnal Pendidikan Jasmani, Olahraga dan Kesehatan), 1(2), 47-59.

Jones, C. M., \& Buxton, A. (2008). Belajar tenis untuk pemula. Bandung: Pionir Jaya.

Kardiawan, I. K. H., Satyawan, I. M., \& Ariawan, K. U. (2018, November). Pengembangan Perangkat Alat Ukur Kekuatan Servis Bola Tenis Lapangan Berbasis Sensor Digital. In Seminar Nasional Riset Inovatif (Vol. 6, pp. 183185).

Kurdi, K., \& Qomarrullah, R. (2020). Hubungan Kecepatan Reaksi Tangan dan Koordinasi Mata Tangan Pada Servis Tenis Lapangan Mahasiswa Universitas Cenderawasih. Jurnal Terapan Ilmu Keolahragaan, 5(1), 22-27. https://doi.org/10.17509/jtikor.v5i1.25060

Meikahani, R., \& Kriswanto, E. S. (2015). Pengembangan buku saku pengenalan pertolongan untuk siswa sekolah menengah pertama. Jurnal Pendidikan Jasmani Indonesia, 11(1), 15-22.

Prasetiono, B. A., \& Gandasari, M. F. (2018). Model Rangkaian Tes Keterampilan Tenis Lapangan pada Pemain Putra Kelompok Usia 12-14 Tahun. Jurnal SPORTIF: Jurnal Penelitian Pembelajaran, 4(2), 220. https://doi.org/10.29407/js_unpgri.v4i2.12498

Prasetyo, A. W. (2017). Pengembangan Buku Elektronik (E-Book) Untuk Pembelajaran Ekstrakurikuler Wajib Pramuka Di Smk Negeri 11 Semarang (Doctoral dissertation, Universitas Negeri Semarang).

Setyawan, T. (2018). Pengembangan Buku Ajar Pendidikan Jasmani Dan Olahraga Melalui Pendekatan Saintifik Kelas Iv Sdn Nguter 02 Lumajang. Jp. Jok (Jurnal Pendidikan Jasmani, Olahraga Dan Kesehatan), 1(2), 24-46.

Siahaan, D. (2017). Pengaruh latihan horizontal swing dan latihan side lateral raise terhadap kemampuan forehand drive dalam permainan tenis lapangan. Jurnal prestasi, 1(2), 23-28.

Slavin, R. E. (2012). Educational Psychology: Theory and Practice. 10th-ed.

Suganda, R., Sutrisno, E., \& Wardana, I. W. (2013). No Title No Title. Journal of Chemical Information and Modeling, 53(9), 1689-1699.

Sugiyono. (2015). Psikologi Kognitif. In Srikandi

Sukadiyanto, S. (2005). Prinsip-Prinsip Pola Bermain Tenis Lapangan. Jurnal Olahraga Prestasi, 1(2), 114595. https://doi.org/10.21831/jorpres.v1i2.6872

Suroso. (2007). Panduan Menulis Artikel \& Jurnal. Yogyakarta: Penerbit Elmatera Publishing

Suryono, S. (2016). Pengaruh metode latihan dan persepsi kinestetik terhadap 
keterampilan groundstrokes tenis lapangan pada siswa SD. Jurnal Keolahragaan, 4(2), 220-231.

Wayan Ardhana dan Verna Wills.(1989). Teknologi Pendidikan. Depdikbud.

Widayati, D. T. (2010). Pedoman Umum Pembelajaran Berbasis Riset (PUPBR). Yogyakarta: Universitas Gadjah Mada.

Winarno, M. E. (2011). Metodologi penelitian dalam pendidikan jasmani. Media Cakrawala Utama Press, Malang. 